\title{
In vitro ANTIOXIDANT, ANTI-INFLAMMATORY AND THROMBOLYTIC PROPERTIES OF LEAF EXTRACT AND FRACTIONS OF Pterocarpus mildbraedii HARMS
}

\author{
"Fajobi, O. A. ${ }^{1}$, Emma-Okon, B. O. ${ }^{2}$, and Oyedapo, O. O. ${ }^{1}$ \\ ${ }^{1}$ Department of Biochemistry and Molecular Biology, ${ }^{2}$ Department of Medical Biochemistry, \\ Obafemi Awolowo University, Ile-Ife, Nigeria \\ *Corresponding author's email: fajobi2009@gmail.com \\ (Received: $6^{\text {th }}$ July, 2020; Accepted: $2^{\text {nd }}$ September, 2020)
}

\section{ABSTRACT}

\begin{abstract}
The study was undertaken to evaluate the in vitro antioxidant, anti-inflammatory and thrombolytic properties of methanolic extract (PMME) and fractions of the leaf of Pterocarpus mildbraedii with a view to exploring the therapeutic potentials of the plant especially as far as treatment and management of oxidative, inflammatory and heart related disorders are concerned. The study involved collection, identification, extraction with $80 \%$ methanol, fractionation of hydromethanolic extract of $P$. mildbraedii leaves with $\mathrm{n}$-hexane, ethyl acetate and $\mathrm{n}$ butanol; evaluation of the contents for total phenolics, flavonoids as well as vitamins $\mathrm{C}$ and E. Evaluation of the antioxidant and anti-inflammatory potentials of the plant using 2, 2'-diphenyl-1-picrylhydrazyl (DPPH), ferric reducing power, hydrogen peroxide reduction, total antioxidant capacity (TAC), and stabilization of erythrocyte membrane and inhibition of albumin denaturation were also carried out. The total phenolic content ranged between $13.31 \pm 0.12$ and $234.99 \pm 2.64 \mathrm{GAE}$ (gallic acid equivalent) $/ \mathrm{g}$, flavonoid content ranged between $44.30 \pm 0.74$ and $228.74 \pm 7.44 \mathrm{QE}$ (quercetin equivalent) $/ \mathrm{g}$, vitamin $\mathrm{C}$ content was $11.98 \pm 0.04 \mathrm{mg} / \mathrm{g}$ while vitamin $\mathrm{E}$ content was $8.62 \pm 0.29 \mathrm{ig} / \mathrm{g}$. The fractions exhibited potent and significant antioxidant and antiinflammatory activities which are concentration-dependent, as well as appreciable thrombolytic activities. Moreover, the extract and fractions compared favourably with various reference drugs used in the study. It was observed that the extract and its fractions possessed bioactive components with beneficial effects in the management of oxidative, inflammatory and heart-related conditions.
\end{abstract}

Keywords: Pterocarpus mildbraedii methanolic extract, Antioxidant, Anti-inflammatory, Thrombolytic, Membrane stability, Haemoglobin, Denaturation.

\section{INTRODUCTION}

Oxidative stress is a disturbance in the equilibrium between the production of free radicals (reactive oxygen and nitrogen species, RONS) and the endogenous defense mechanisms (antioxidants) in favour of the production of oxidant species. The body generates free radicals (oxidants) as part of normal metabolic processes, regulation of body functions and signal transduction (Sharma, 2014). This includes generation of energy in the mitochondria through oxidative phosphorylation, detoxication of xenobiotics by cytochrome $\mathrm{P}_{450}$ using oxidizing enzymes, apoptosis of defective cells, regulation of cellular function, acting as second messengers for destruction of microorganisms by macrophages (Pham-Huy et al., 2008; Sharma, 2014). Free radicals so generated are capable of damaging important cellular components like protein, DNA, carbohydrates and membrane lipids, as well as causing damage to endothelial cells and leading to a cascade of inflammatory reactions.
The body counteracts oxidative stress by producing enzymatic and non-enzymatic antioxidants, which are compounds/molecules that delay autoxidation and propagation of free radicals by one (or more) of several mechanisms which includes (i) scavenging species that initiate peroxidation (ii) chelating metal ions such that they are unable to generate reactive species or decompose lipid peroxides (iii) quenching superoxide ions thus preventing formation of peroxides (iv) breaking the auto-oxidative chain reaction and/or (v) reducing localized $\mathrm{O}_{2}$ concentrations. Antioxidants also donate their electrons to stabilize free radicals and make them stable compounds so as to minimize their harmful effects (Brewer, 2011; Obeagu, 2018). Oxidative stress has been implicated in a number of pathological conditions such as cancer, diabetes, neurological disorders, metabolic disorders and cardiovascular diseases (Qazi and Molvi, 2018). 
Many plant products (fruits and vegetables) have been reported to possess antioxidants capable of eliminating, inhibiting or stabilizing free radicals (Pisoschi and Negulescu, 2011). Some of such plants found in sub-Saharan Africa include Cleome nutidosperma, Emilia coccinea, Euphorbia heterophylla, Physalis angulata, Scopania dulcis, Richardia bransitensis, Spigella anthelmia, Tridax procumbens, Blighia sapida, Erythrophleum suaveolens, Lecaniodiscus cupanioides, Moringa oleifera, Nauclea diddericchii, Pterocarpus soyanii (Edeoga et al., 2005; Lawal et al., 2010).

P. mildbraedii (commonly called Red sandal wood) is classified as part of the family Papilionaceae, grows in the lowland rainforest, dry evergreen and riverine forests in Nigeria, Sierra Leone, Ghana, Cameroon, Equatorial Guinea and Tanzania. It is a semi-wild tree which mostly exists in the wild but scantly seen in households and seldom cultivated by farmers (Okoli et al., 2015). The plant grows to about $15-25 \mathrm{~m}$ tall and having stem diameter of up to $20 \mathrm{~m}$. It has smooth brown bark and slowly releases red gum when cut (Usunobun and Igwe, 2016). The young and tender leaf of P. mildbraedii is widely consumed for its therapeutic and medicinal values and is recommended for use to prevent diabetes and treatment of headaches, pains, fever and convulsions (Ucheghu et al., 2015). While few studies have suggested that the plant contains phytochemicals such as phenolics and flavonoids which indicate that it could serve as an antioxidant, hypocholesterolemic, antimicrobial or cardioprotective agent (Ucheghu et al., 2015; Usunobun and Igwe, 2016), this study seeks to further investigate the antioxidant, antiinflammatory and thrombolytic activities of the plant to ascertain the value of its use as a therapeutic agent.

\section{MATERIALS AND METHODS}

\section{Reagents and Chemicals}

All reagents and chemicals used for this study were of analytical grade from various manufacturers.

\section{Preparation of Methanol Extract of $P$. mildbraedii \\ Young fresh leaves were collected from Ajebandele, Ile-Ife, Nigeria. The plant was identified and authenticated at IFE Herbarium, Department of Botany, Obafemi Awolowo}

University (OAU), Ile-Ife, where specimen number (IFE-17722) was given. The methanolic extract was prepared according to the method of Oyedapo and Amos (1997). The leaves were cut into bits, air-dried, pulverized and suspended in $80 \%(\mathrm{v} / \mathrm{v})$ methanol for $72 \mathrm{hr}$ at room temperature with occasional stirring and then filtered. The residue was further extracted with the same solvent until the extract became colourless. The extracts were pooled together, filtered and concentrated in vacuo to slurry under reduced pressure at $40{ }^{\circ} \mathrm{C}$ on rotary evaporator (Rotavapor RII, BUCHI Switzerland). The slurry was dispensed into clean petri dishes and exposed to air to obtain dark brown residue termed $P$. mildbraedii methanol extract (PMME) and kept in the desiccator for further use.

\section{Fractionation of Methanol Extract using Solvent Partition Technique}

The methanol extract was partitioned according to a procedure that was based on earlier reported method (Oyedapo et al., 2010) using solvents of increasing polarities. PMME (21 g) was suspended in hot distilled water $(100 \mathrm{ml})$, allowed to dissolve, filtered and partitioned sequentially in a separating funnel with $\mathrm{n}$-hexane $(500 \mathrm{ml} \times 6)$. The hexane fractions were pooled together and concentrated to dryness under reduced pressure to yield hexane fraction (HF). The aqueous layer was partitioned with ethyl acetate $(500 \mathrm{ml} \times 13)$. The ethyl acetate fractions were pooled together and concentrated to dryness under reduced pressure to yield ethyl acetate fraction (EAF). The aqueous layer was further partitioned with n-butanol (500 $\mathrm{ml}$ x 20), fractions pooled together and concentrated to dryness under reduced pressure to yield butanol fraction (BF). The aqueous layer remaining was concentrated to dryness under reduced pressure to yield aqueous fraction $(\mathrm{AqF})$.

\section{Biochemical Analyses \\ A: Evaluation of Antioxidant Potentials}

Spectrophotometric methods were used to evaluate the antioxidant potentials of the methanol extract and fractions: total phenolics (mg TAE/g extract) (Singleton et al., 1999), total flavonoid (mg QE/g extract) (Sun et al., 1999), vitamin C (mg/g) (Japota and Dani 1982) and vitamin $\mathrm{E}(\mu \mathrm{g} / \mathrm{g})$ (Santhosh et al., 2013). 


\section{B: Evaluation of Antioxidant Activities}

The DPPH-radical scavenging activities of the extract and its fractions were carried out according to the procedure of Blois (1985). The percentage DPPH radical scavenging activity was calculated using the expression:

Percentage Scavenging Activity $=$

$\frac{A b s_{\text {control }}-A b s_{\text {sample }}}{A b s_{\text {control }}} \times 100$

The reducing power was measured according to the procedure of Oyaizu (1986), increased absorbance of the reaction mixture indicated increased reducing power; total antioxidant capacity (TAC) was based on those of Prieto et al. (1999) and Aliyu et al. (2012). The antioxidant capacity of the extract and fractions was expressed as the number of milligram equivalent of ascorbic acid (mg AAE).

The hydrogen peroxide radical scavenging assay activity was carried out according to a procedure that was based on the method reported by Archana and Vijayalakshmi (2018). Ascorbic acid was used as standard and the percentage inhibition was calculated using the expression below:

Percentage Inhibition $=$

$\frac{A b s_{\text {test }}-A b s_{\text {control }}}{A b s_{\text {test }}} \times 100$

\section{C: Evaluation of Anti-inflammatory Activities}

Evaluation of the anti-inflammatory activities was carried out using

(I): inhibition of albumin denaturation according to the procedure of Mizushima and Kobayashi (1968) and Aina and Oyedapo (2013). The percentage inhibition was calculated as:

Quantity of protein left $=$

$$
\frac{A b s_{\text {test }}-A b s_{\text {control }}}{A b s_{\text {test }}}
$$

Percentage of inhibition $=$

$\frac{\text { Quantity of protein left }}{\text { Total protein }} \times 100$

(ii): membrane stabilizing activity assay of the extract and fractions was based on an earlier procedure (Oyedapo et al., 2010). Ibuprofen (an anti-inflammatory drug) was used as standard and the percentage membrane stability was calculated as:

Percentage membrane stability $=[100-$

$\frac{\left.A b s_{\text {drug test }}-A b s_{\text {drug control }}\right]}{A b s_{\text {blood control }}} \times 100$

The blood control represented 100\% lysis.

\section{D: Assay of Thrombolytic Activity}

The thrombolytic activity was carried out to assess the in vitro clot lysis potential of the $P$. mildbraedii methanolic extract and its fractions according to the method reported by Reyad-ul-Ferdous et al. (2014). Briefly, venous human blood $(500 \mu \mathrm{l})$ was collected into sterile pre-weighed Eppendoff tubes $\left(\mathrm{M}_{1}\right)$, left for $45 \mathrm{~min}$ to coagulate at room temperature, centrifuged at $3000 \mathrm{rpm}$ for $5 \mathrm{~min}$ and the serum was completely removed. The blood clots were weighed $\left(\mathrm{M}_{2}\right)$, the extract and fractions $(100 \mu \mathrm{l}, 1 \mathrm{mg} / \mathrm{ml})$ were added and

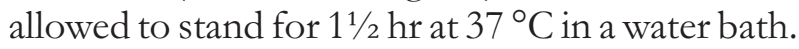
The released fluid was removed after incubation and tubes containing the blood clot was reweighed $\left(\mathrm{M}_{3}\right)$. Aspirin $(1 \mathrm{mg} / \mathrm{ml})$ was used as standard.

Percentage clot lysis was calculated using the formula:

Percentage of clot lysis $=$

$\frac{\text { weight of released clot }\left(M_{3}-M_{1}\right)}{\operatorname{clot} \text { weight }\left(M_{2}-M_{1}\right)} \times 100$

\section{Statistical Analysis}

Data was analysed using Microsoft Excel 2010 and Graph Pad Prism 5, and expressed as Mean \pm SEM, $\mathrm{n}=5$.

\section{RESULTS}

A: Concentrations of Antioxidant Potentials in PMME and Fractions of $P$. mildbraedii

Table 1 gives a summary of the antioxidant potentials (phenolics, flavonoids, vitamin $\mathrm{C}$ and vitamin $\mathrm{E}$ ) of the extract and different fractions of leaf of P. mildbraedii. It was noted that the plant is very rich in vital bioactive metabolites that 
possess and exhibit potent antioxidant and antiinflammatory activities. Also, in table 2 is the summary of the total antioxidant capacities of the extract and its fractions revealing that all the fractions possess and exhibit significant antioxidant capacities. The aqueous fraction has the highest antioxidant capacity.

\section{B: Antioxidant Activities of PPME and its Fractions}

Figures 1-3 depict the antioxidant activities of the leaf extract and fractions of $P$. mildbraedii on $\mathrm{DPPH}$ - radical scavenging, ferric reducing antioxidant power, and hydrogen peroxide inhibition activities. It was observed that the PPME and its fractions exhibit potent and significant activities. The antioxidant activity was found to be in the following order; ethyl acetate fraction $>$ aqueous fraction $>$ methanolic extract $>$ butanol fraction $>$ hexane fraction for the three models. Moreover, the activities were concentration-dependent and compared favourably with those of the standard reference (ascorbic acid).

\section{C: Anti-inflammatory Activities of PPME and its Fractions}

Figures 4 and 5 depict the anti-inflammatory activities of the PPME and its fractions using inhibition of denaturation of albumin and red blood cell membrane stabilizing activity exposed to both heat and hypotonic-induced lyses models. The percentage inhibition of albumin denaturation of the PPME, its fractions and aspirin (a standard non-steroidal antiinflammatory drug) was aspirin (32.77 $\pm 1.43 \%)$, PPME (73.46 $\pm 0.49 \%$ ), hexane fraction (41.82 \pm $2.42 \%)$, ethyl acetate fraction (84.91 $\pm 0.19 \%)$, butanol fraction $(73.26 \pm 0.48 \%)$ and aqueous fraction $(68.16 \pm 0.28 \%)$. The albumin denaturation inhibition was observed to be concentration-dependent which implied that as concentration increases percentage inhibition also increased proportionally.

Figure 5 is a summary of the stabilizing effect of the extract and fractions on red blood cell membrane exposed to both heat and hypotonic lyses. It was observed that ethyl acetate fraction exhibited the highest range of activity (11.38 \pm 0.55 and $74.23 \pm 1.06 \%)$, PPME $(30.74 \pm 14.77$ and $73.83 \pm 1.21 \%)$, hexane fraction $(56.45 \pm 2.91$ and $60.28 \pm 0.23 \%)$, aqueous fraction $(11.22 \pm$ 0.45 and $30.47 \pm 11.42 \%$ ), and butanol fraction the least activity $(3.06 \pm 1.69$ and $13.69 \pm 1.13 \%)$ as against ibuprofen, the standard antiinflammatory drug $(8.38 \pm 0.88$ and $17.73 \pm 4.62)$. The mode of protection exhibited by PPME, its fractions and ibuprofen was monophasic.

\section{D: Thrombolytic Activity}

Figure 6 depicts the thrombolytic activities of the PPME and its fractions as expressed in percentage of clot lysis. These results reveal that the leaf extract of the plant and its fractions could be good thrombolytic agents and good candidates for the development of agents in the management and treatment of cardiovascular disorders.

Table 1: Antioxidant Potentials of Methanol Extract and Fractions of P. mildbraedii

\begin{tabular}{lccccc}
\hline \multicolumn{1}{c}{ Molecule } & $\begin{array}{c}\text { Methanol } \\
\text { Extract }\end{array}$ & $\begin{array}{c}\text { Hexane } \\
\text { Fraction }\end{array}$ & $\begin{array}{c}\text { Ethyl acetate } \\
\text { Fraction }\end{array}$ & $\begin{array}{c}\text { Butanol } \\
\text { Fraction }\end{array}$ & $\begin{array}{c}\text { Aqueous } \\
\text { Fraction }\end{array}$ \\
\hline $\begin{array}{l}\text { Total Phenolics } \\
\text { (mgGAE/g) }\end{array}$ & $189.07 \pm 0.94$ & $13.31 \pm 0.12$ & $234.99 \pm 2.64$ & $94.99 \pm 0.60$ & $101.19 \pm 0.40$ \\
$\begin{array}{l}\text { Total Flavonoids } \\
(\mathbf{m g Q E} / \mathbf{g})\end{array}$ & $49.85 \pm 1.34$ & $44.30 \pm 0.74$ & $228.74 \pm 7.44$ & $63.93 \pm 0.37$ & $108.00 \pm 1.28$ \\
$\begin{array}{l}\text { Vitamin C } \\
(\mathbf{m g} / \mathbf{g})\end{array}$ & $11.98 \pm 0.04$ & & & & \\
Vitamin E $(\boldsymbol{\mu g} / \mathbf{g})$ & $8.62 \pm 0.29$ & & & & \\
\hline
\end{tabular}

Each value represented the Mean \pm SEM of 5 determinations

GAE- gallic acid equivalent; QE- quercetin equivalent 
Table 2: Total Antioxidant Capacity of Methanol Extract and Fractions of P. mildbraedii

\begin{tabular}{lc}
\hline Extract/Fraction & $\begin{array}{c}\text { Total Antioxidant Capacity } \\
\text { (mgAAE/g) }\end{array}$ \\
\hline Methanol & $103.94 \pm 1.85$ \\
Hexane & $278.94 \pm 10.03$ \\
Ethyl acetate & $436.81 \pm 1.60$ \\
Butanol & $430.79 \pm 9.22$ \\
Aqueous & $503.47 \pm 11.02$ \\
\hline
\end{tabular}

Each value represented the Mean \pm SEM of 5 determinations AAE (Ascorbic Acid Equivalent)

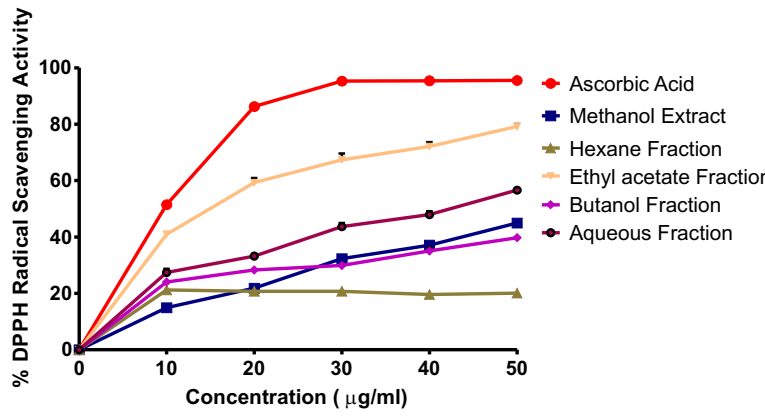

Figure 1: DPPH Scavenging Activities of PPME and Fractions of Leaf of $P$. mildbraedii

Each value represented the Mean \pm SEM of 5 determinations

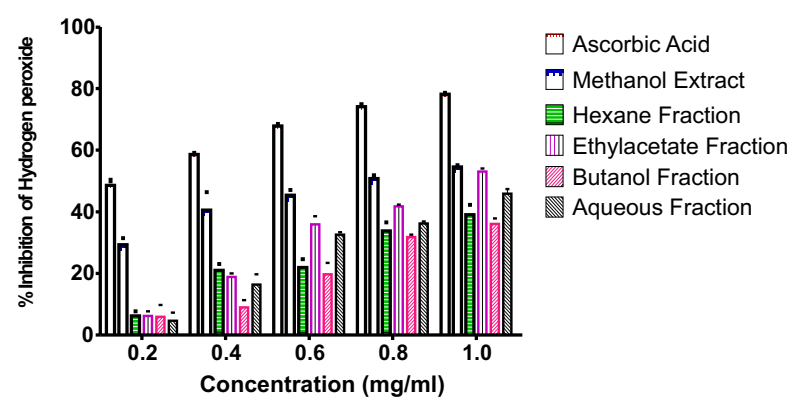

Figure 3: Inhibition of Hydrogen Peroxide by PPME and Fractions of $P$. mildbraedii Each value represented the Mean \pm SEM of 5 determinations

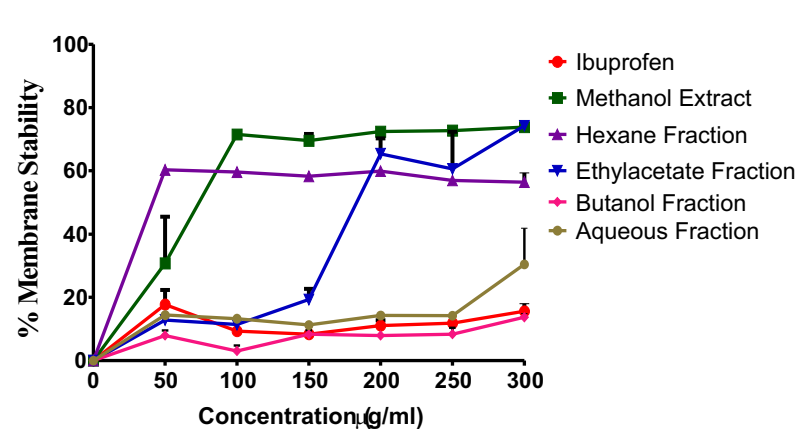

Figure 5: Membrane Stabilizing Potential of PPME and Fractions of $P$. mildbraedii Each value represented the Mean \pm SEM of 5 determinations

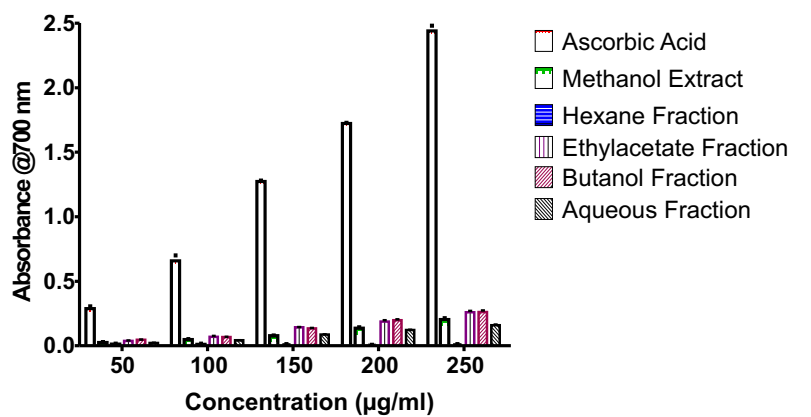

Figure 2: Ferric Reducing Antioxidant Power of PPME and Fractions of P. mildbraedii Each value represented the Mean \pm SEM of 5 determinations

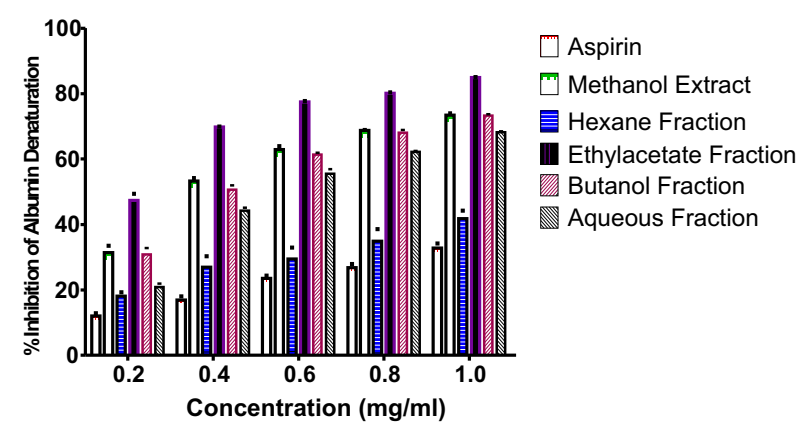

Figure 4: Inhibition of Albumin Denaturation of PPME and Fractions of P. mildbraedii Each value represented the Mean \pm SEM of 5 determinations

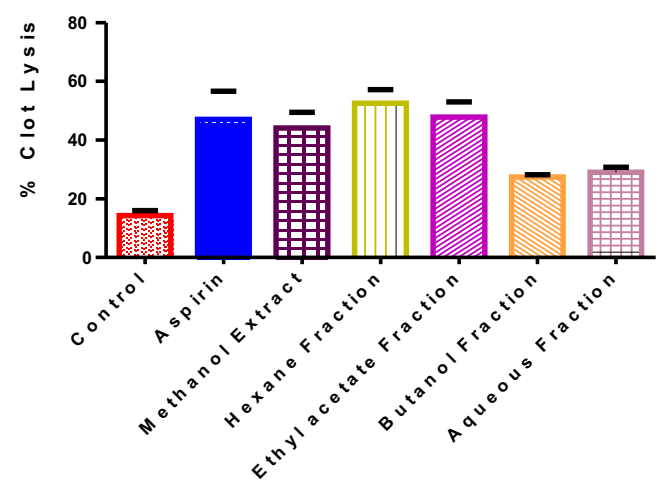

Figure 6: Thrombolytic Effect of Methanol Leaf Extract of P. mildbraedii and its Fractions Each value represented the Mean \pm SEM of 5 determinations 


\section{DISCUSSION}

Naturally occurring phenolics found in fruits and vegetables have been found to possess and exhibit different properties ranging from antioxidants, anti-inflammatory, anti-proliferative, anti-cancer, anti-spasmodic, anti-depressant, anti-ulcer and protection against chronic and degenerative diseases such as cardiovascular diseases (Yadav et al., 2016; Ravimannan and Nisansala, 2017).

The antioxidant potentials of the $P$. mildbraedii extract and the fractions were determined by $\mathrm{DPPH}$ scavenging activity, ferric reducing antioxidant power, hydrogen peroxide scavenging activity and total antioxidant capacity and compared with standard ascorbic acid. DPPH is a stable free radical and widely employed to test the ability of compounds/agents to scavenge radicals. It is the easiest, fastest and most convenient ways of evaluating antioxidants and radical scavenging activity of plant extracts (Usunobun and Igwe, 2016; Archana and Vijayalakshmi, 2018).

The percentage DPPH scavenging power of the extract and fractions was concentrationdependent, which implies that as concentrations of the extract and fractions increase the percentage radical scavenging increased. It was observed that the ethyl acetate fraction was the most potent and comparable to the standard ascorbic acid. The results of this study agreed with the previous reports of Usunobun and Igwe (2016) and Yembeau et al. (2018) who observed concentration-dependent DPPH scavenging activities for extracts of $P$. mildbraedii and Theobroma cacao respectively.

Ferric reducing antioxidant power (FRAP) is another model employed to assess antioxidant properties of phytochemicals and is based on the reddish-brown colour of $\mathrm{Fe}^{3+}$ being changed to green when reduced, with increasing absorbance representing an increase in reducing ability of an agent or compound (Oyaizu, 1986). The reducing ability of PMME and fractions was also concentration-dependent and in agreement with earlier results of Usunobun and Igwe (2016) which reported that the reducing ability of aqueous extract of $P$. mildbraedii leaf was exerted by the donation of a hydrogen atom in breaking the free radical chain.
Olarewaju et al. (2018) reported that the ferric reducing antioxidant power of aqueous leaf extracts of Solanum macrocarpon, Amaranthus viridis and Telfairia occidentalis were also concentrationdependent. The total antioxidant capacity (TAC) of the PMME and fractions shows that the vegetable can be employed as a source of both water-soluble and fat-soluble antioxidants (Aliyu et al., 2012). This observation is in agreement with the report of Olarewaju et al. (2018) which stated that TAC reflects the synergistic interactions of compounds present in a vegetable and also an index that describes ability of the antioxidants to neutralize preformed free radicals. Potential et al. (2016) also reported that the TAC of a vegetable is basically due to the flavonoids and other polyphenol contents in the plant.

Hydrogen peroxide, a weak oxidizing agent which inactivates some enzymes by the oxidation of essential thio (-SH) groups, can sometimes be toxic to the cell when it crosses the cell membrane giving rise to hydroxyl radicals through the Fenton reaction (Archana and Vijayalakshmi, 2018). The inhibition of hydrogen peroxide ability of the extract and its fractions is in agreement with a previous study which reported dose-dependent inhibition of hydrogen peroxide by phloroglucinol, a polyphenol component of Laminariaceae family (Archana and Vijayalakhmi, 2018). It is surmised that consumption of $P$. mildbraedii could be beneficial in preventing oxidative stress related degenerative disorders.

Inflammation is a normal complex response to tissue injuries to stimuli triggered by physical microbial infections, heat and chemical injuries (Ashley et al., 2012; Akinwunmi and Oyedapo, 2015). It is a protective attempt by the body to eliminate injurious stimuli as well as initiate the healing process for the tissues (Ashley et al., 2012). Denaturation of protein is one of the causes of rheumatoid arthritis. The mechanism of denaturation probably involves alteration of the bonds associated with the tertiary structure of proteins. It has been well established that denaturation of tissue proteins leads to inflammatory disorders such as arthritis (Williams etal., 2008).

Studies have revealed that steroidal and non- 
steroidal anti-inflammatory drugs usually employed in the treatment and management of inflammatory conditions are not devoid of adverse effects such as ulcer and gastric irritation (Oyedapo et al., 2010; Sakat et al., 2010). Plant products that exhibit abilities to prevent or inhibit protein denaturation would serve as an antiinflammatory agent and be considered for the development of anti-inflammatory agents (Osman et al., 2016). It was observed from the study that the extract and fractions exhibited a dose-dependent inhibition of albumin denaturation, with ethyl acetate fraction showing the highest activity. The inhibition of heatinduced denaturation of albumin was observed to be concentration-dependent and compared with the standard drug ibuprofen. It implied that antiinflammatory activity of PMME and fractions could be due to the presence of phenolic and related molecules in them. Other plants which have been reported to exhibit anti-inflammatory properties through inhibition of albumin denaturation include Monodora myristica (Akinwunmi and Oyedapo, 2015) and Oxalis corniculata (Sakat et al., 2010). This antiinflammatory activity might be through the inhibition of the release of lysosomal content of neutrophils at the site of inflammation (Sakat et al., 2010; Akinwunmi and Oyedapo, 2015).

The vitality of cells depending on the integrity of their membranes is an established factor and the exposure of red blood cells to injuries such as heat and hypotonic medium leads to the lysis of their membrane associated with hemolysis (Aina and Oyedapo, 2013; Tantary et al., 2017). Stabilization of erythrocyte membrane, an analogue of lysosomal membrane is important in mimicking the inflammatory response by inhibiting the release of lysosomal constituents of activated neutrophils like proteases and bactericidal enzymes which cause further tissue damage. Injury caused to erythrocyte membrane would further render the cell more susceptible to secondary damage through free radical-induced lipid peroxidation. Stabilization of erythrocyte membrane exposed to both hypotonic and heatinduced lyses by the extract and its fractions as investigated in this study revealed that $P$. mildbraedii leaf showed a dose-dependent membrane stabilizing activity over the concentration ranges tested. This result compared favourably with the activity of ibuprofen.

The potency of the extract could be as a result of synergistic activities of its many constituents and that of ethyl acetate fraction due to the high content of its polyphenol constituents (Oyedapo et al. 2010; Umapathy et al., 2010). This is in agreement with earlier studies (Aina and Oyedapo, 2013; Akinwunmi and Oyedapo, 2015) who reported the abilities of extract of seeds of Monodora myristica and Cyclosorus afer to stabilize erythrocyte membrane exposed to both heat and hypotonic-induced lyses. The activities were dosedependent and due to the presence of naturally occurring flavonoids. Sakat et al. (2010) also reported the dose-dependent stabilizing activity of Oxalis corniculata on erythrocyte membrane exposed to heat induced lysis.

Thrombosis is the formation of a typical mass (blood clot) in the artery of a living vascular system linked with myocardial infarction and stroke, while thrombolysis is the breakdown of blood clots through pharmacological means involving thrombolytic drugs which dissolve clots (Tanvir et al., 2015, Jakaria et al., 2017). The most commonly used thrombolytic drug is aspirin, whose use is limited and which has to be administered in low dose as a result of attendant side effects due to inhibition of prostanoids which have protective effects on the gastrointestinal mucosa. It is therefore desirable to find natural products which will exert thrombolytic effect with little or no unwanted side effects. In this study, it was observed that $P$. mildbraedii extract and its fractions exhibited substantial and significant thrombolytic potentials which compared favourably with the reference standard drug (aspirin). This is an important finding which may have significant implication in cardiovascular health, particularly in atherothrombotic patients (Reyad-ul-Ferdous et al., 2014; Tanvir et al., 2015). It will however be necessary to study the structural properties of the active compounds responsible for this activity and investigate their mechanism of action.

\section{CONCLUSION}

The results of our investigations reveal that the leaves of $P$. mildbraedii contain vital bioactive 
metabolites including phenolic compounds with significant antioxidant and anti-inflammatory activities which could be helpful in the management of oxidative and inflammatory disorders as well as serving as potent thrombolytic agent.

\section{REFERENCES}

Aina, O.I. and Oyedapo, O.O. 2013. In vitro investigations into the antioxidant and anti-inflammatory potential of the fractions and ethanolic extract of Cyclosorus afer (Christ.) Ching, stalks. Ife Journal of Science, 15(2): 235-249.

Akinwunmi, K.F. and Oyedapo, O.O. 2015. In vitro anti-inflammatory evaluation of African nutmeg (Monodora myristica) seeds. European Journal of Medicinal Plants, 8(3): 176-174.

Aliyu, A.B., Ibrahim, M.A., Ibrahim, H., Musa, A.M., Lawal, A.Y., Oshanimi, J.A., Usman, M., Abdulkadir, I.E., Oyewale, A.O. and Amupitan, J.O. 2012. Free radical scavenging and total antioxidant capacity of methanol extract of Ethulia conyzoides growing in Nigeria. Romanian Biotechnological Letters, 17(4): 7458-7465.

Archana, I. and Vijayalakshmi, K. 2018. Antioxidant Potential of Phloroglucinol: An In-Vitro Approach. International Journal of Pharmaceutical Sciences and Research, 8 (7): 2947-2951.

Ashley, N.T., Well, Z.M. and Nelson, R.J. 2012. Inflammation: Mechanisms, costs, and natural variation. Annual review of Ecology, Evolution and Systematics, 43: 385-406.

Blois, M.S. 1985. Antioxidant determination by use of stable free radicals. Nature, 29: 1199-1200.

Brewer, M.S. 2011. Natural antioxidants: Sources, compounds, mechanisms of action, and potential applications. Comprehensive Reviews in Food Science and Food Safety, 10: 221-247.

Edeoga, H.O., Okwu, D.E. and Mbaebie, B.O. 2005. Phytochemical constituents of some Nigerian medicinal plants. African Journal of Biotechnology, 4(7): 685- 688.

Jakaria, M., Mukimul, I., Sariful, I., Mohammad, B.T., Chayan, D.C. and Mohammed, I. 2017. Thrombolysis potential of methanol extracts from the five medicinal plants leaf available in Bangladesh. Pharmacologia, 8: 78-82.

Japota, S.K. and Dani, H.M. 1982. A new colorimetric technique for the estimation of vitamin C using Folin-CIocalteau's phenol reagent. Analytical Biochemistry, 127: 178-182.

Lawal, I.O., Uzokwe, N.E., Igboanugo, A.B.I., Adio, A.F., Awosan, E.A., Nwogwugwu, J.O., Faloye, B., Olatunji, B.P. and Adesoga, A.A. 2010. Ethno medicinal information on collation and identification of some medicinal plants in Research Institutes of South-west Nigeria. African Journal of Pharmacy and Pharmacology, 4(1): 1-7.

Mizushima, Y. and Kobayashi, M. 1968. Interaction of anti-inflammatory drugs with serum proteins, especially with some biologically active proteins. Journal of Pharmacy and Pharmacology, 20:169-173.

Obeagu, E.I. 2018. A Review on Free Radicals and Antioxidants. International Journal of Current Research in Medical Sciences, 4(2): 123-133.

Okoli, N.A., Obiefuna, J.C., Obasi, A.Z., Ibeawuchi, I.I., Ihejirika, G.O., Alagba, R.A., Emma-Okafor, L.C., Offor, M.O. and Peter-Onoh, C.A. 2015. Nursery techniques for the propagation of Pterocarpus mildbraedii Harms (Oha ojii) in Owerri West, Southern Nigeria. FUTO Journal Series (FUTOJNLS), 1(2): 98-102.

Olarewaju, O.A., Alashi, A.M., Taiwo, K.A., Oyedele, D., Adebooye, O.C. and Aluko, R.E. 2018. Influence of nitrogen fertilizer micro-dosing on phenolic content, antioxidant, and anticholinesterase properties of aqueous extracts of three tropical leafy vegetables. Journal of Food Biochemistry, 42:1-13.

Osman, N.I., Sidik, N.J., Awal, A., Adam, N.A.M. and Rezali, N.I. 2016. In vitro Xanthine oxidase and albumin denaturation inhibition assay of Barringtonia racemosa $\mathrm{L}$. and total phenolic content analysis for potential anti-inflammatory use in gouty arthritis. Journal of International Ethnopharmacology, 343-349.

Oyaizu, M. 1986. Studies on product of browning 
reaction prepared from glucose amine. Japanese Journal of Nutrition, 44:307-315.

Oyedapo, O.O. and Amos, S. 1997. Further investigations into the bioactivity of root extract of Plumbago zeylanica. Phytotherapy Research, 11: 62-63.

Oyedapo, O.O., Akinpelu, B.A., Akinwunmi, K.F., Adeyinka, M.O. and Sipeolu, F.O. 2010. Red blood cell membrane stabilizing potentials of extracts of Lantana camara and its fractions. International Journal of Plant Physiology and Biochemistry, 2(4): 46-51.

Pham-Huy, L.A., He, H. and Pham-Huy, C. 2008. Free Radicals, Antioxidants in Disease and Health. International Journal Biomedical Science, 4(2): 89-96.

Pisoschi, A.M. and Negulescu, G.P. 2011. Methods for Total Antioxidant Activity Determination: A Review. Biochemistry and AnalyticalBiochemistry, 1:106.

Potential, P., View, M.P., People, G., Ttcc, U., View, T. and Uddin, S. 2016. Analysis of in vitro antioxidant activity of Caryota urens L. leaves: A traditional natural remedy. Journal of Coastal Life Medicine, 4(6): 483489.

Prieto, P., Pineda, M., Anguilar, M. 1999. Spectrophotometric quantitation of antioxidant capacity through the formation of a Phosphomolybdenum Complex: Specific application to the determination of Vitamin E. Analytical Biochemistry, 269:337-341.

Qazi, M.A. and Molvi, K.I. 2018. Free Radicals and their Management. American Journal of Pharmacy and Health Research, 6(4): 1-11.

Ravimannan, N. and Nisansala, A. 2017. Study on antioxidant activity in fruits and vegetables: A review. International Journal of Advanced Research in Biological Sciences, 4(3): 93-101.

Reyad-ul-Ferdous, M., Alam, T.T., Islam, M.A., Khan, M.Z.I. and Tasnim, F. 2014. Ex-vivo cardioprotective and cytotoxic screening of fruits of Parmentiera cereifera seem. Biology and Medicine, 6:1-3.

Sakat, S.S., Juvekar, A.R. and Gambhire, M.N. 2010. In vitro antioxidant and antiinflammatory activity of methanol extract of Oxalis corniculata Linn. International Journal of Pharmacy and Pharmaceutical
Sciences, 2(1): 146-155.

Santhosh, K.S., Samydurai, P., Ramakrishman, R. and Nagarajan, N. 2013. Polyphenols, Vitamin-E Estimation and in vitro Antioxidant Activity of Adriantum capilluveneris. International Journal of Innovative Pharmacentical Research, 4 (1):258-262.

Sharma, N. 2014. Free Radicals, Antioxidants and Disease. Biology and Medicine, 6:214.

Singleton, V.L., Orthofera, R. and Lamuela, R.R.M. 1999. Analysis of total phenols and other oxidation substrates and antioxidants by means of FolinCiocalteu's reagent. Methods in Ensymology, 299: 152-179.

Sun, P.X., Yie, L.K., Zhang, Z.L., Hu, M. and Lu, L. 1999. Colometric determination of the total content of the flavonoids in epimedium capsules. Journal of Shenyang Pharmaceutical University, 16: 68-70.

Tantary, S., Masood, A., Bhat, A.H., Dar, K.B., Zargar, M.A. and Ganle, S.A. 2017. In vitro antioxidant and RBC membrane stabilization activity of Euphorbia wallichii. Free Radicals and Antioxidants, 7(1): 13-22.

Tanvir, A.C., Kamal, A.T.M.M., Kazi, A.A.C., Afrina, J., Shakhawat, H., Arafatul, M., Mahmudul, H. and Javed, H. 2015. Cytotoxic and thrombolytic activity of methanolic extract of Macaranga denticulate bark. The Parma Innovation Journal, 4(5): 3639.

Ucheghu, R.I., Iwuoha, G.U., Elenwoke, U.E., Ibe, C.O. and Amanze, K.O. 2015. Identification of Phytochemicals Present in the Leaves of Pterocarpus mildbraedii Harms by GC/MS Analysis. IOSR Journal of Applied Chemistry, 8(7): 9-10.

Umapathy, E., Ndebia, E.J., Meeme, A., Adam, B., Menziwa, P., Nkeh-Chungaga, N.B. and Iputo, J.E. 2010. An experimental evaluation of Albuca setosa aqueous extract on membrane stabilization, protein denaturation and white blood cell migration during acute inflammation. Journal of Medicinal Plants Research, 4: 789795.

Usunobun, U. and Igwe, V.C. 2016. Phytochemical screening, mineral composition and in vitro antioxidant activities of Pterocarpus mildbraedii leaves. International Journal of 
074 Fajobi et al.: In vitro Antioxidant, Anti-Inflammatory and Thrombolytic Properties of Leaf Extract

Scientific World, 4(1): 23-26.

Williams, H., Walker, D. and Orchard, T. R. 2008. Extraintestinal manifestations of inflammatory bowel disease. Current Gastroenterology Reports, 10: 597-605.

Yadav, A., Kumari, R., Yadav, A., Mishra, J.P., Srivatva, S. and Prabha, S. 2016. Antioxidants and its functions in human body- A review. Review in Environment and Life Sciences, 9(11): 1328-1331.
Yembeau, N.L., Biapa, P.C.N., Chetcha, B., Nguelewou, F.L., Kengne, F., Nkwikeu, P.J.N., Telefo, P.B. and Pieme, C.A. 2018. In vitro evaluation of antioxidant and antisickling properties of Theobroma cacao (Sterculiaceae) extract from east and south regions in Cameroon. Investigational Medicinal Chemistry and Pharmacology, 1(1): 1-9. 